Chapter 15

\title{
Cartilage Tissue Engineering: The Role of Extracellular Matrix (ECM) and Novel Strategies
}

\author{
Zaira Y. García-Carvajal, David Garciadiego-Cázares, \\ Carmen Parra-Cid, Rocío Aguilar-Gaytán, \\ Cristina Velasquillo, Clemente Ibarra and \\ Javier S. Castro Carmona
}

Additional information is available at the end of the chapter

http://dx.doi.org/10.5772/55917

\section{Introduction}

Articular cartilage is a hyaline cartilage that consists primarily of extracellular matrix with a sparse population of cells, lacking blood vessels, lymphatic vessels and nerves. The only cell type within cartilage is the chondrocyte and has a low level of metabolic activity with little or no cell division and is the responsible for maintaining in a low-turnover state the unique composition and organization of the matrix that was determined during embryonic and postnatal development. The biological and mechanical properties of articular cartilage depend on the interactions between the chondrocytes and the matrix that maintain the tissue. Chondrocytes form the macromolecular framework of the tissue matrix from three classes of molecules: collagens, proteoglycans, and non-collagenous proteins and maintain the extracellular matrix (ECM) by low-turnover replacement of certain matrix proteins $[1,2]$.

Aggrecan and type II collagen are the most abundant proteins found within the ECM in the articular cartilage and they are linked together by a number of collagen-binding proteins including cartilage oligomeric matrix protein (COMP), chondroadherin and other minor collagens on their surface. Aggrecan is a large aggregating proteoglycan which is in association with hyaluronan (HA) and link protein (LP). These aggregates are responsible for the turgid and they provide the osmotic properties to resist compressive loads and retain water. Also contain a variety of small leucine-rich repeat proteoglycans (SLRPs) as decorin, biglycan, fibromodulin and lumican where they help maintain the integrity of the tissue and modulate its metabolism $[3,4]$. 


\section{Alteration in cartilage composition in Osteoarthritis (OA)}

The chondrocyte is responsible for both the synthesis and the breakdown of the cartilaginous matrix but the mechanisms that control this balance are poorly understood [4]. The distribution of load across the joint is an important function of the articular cartilage for avoid excessive load affecting both cartilage and bone. It has been demonstrated that articular chondrocytes are able to respond to mechanical injury where biological stimuli such as cytokines and growth and differentiation factors contribute to structural changes in the surrounding cartilage matrix. It has been demonstrated that many non-mechanical and mechanical factors such as load clearly have a role in the initiation and propagation the processes of OA. The OA is the most common joint disease allowing dysfunction and pain. The OA is characterized by changes in chondrocyte metabolism that leads to elevated production of proteolytic enzymes, cartilage damage and loss of joint function. It have been described several mechanisms that can lead to $\mathrm{OA}$, among of these mechanisms are mechanicals, bone changes and changes in the cartilage extracellular matrix $[5,6]$

Aging, cartilage senescence and reactive oxygen species (ROS) are normal changes in the musculoskeletal system that contribute to the development of OA, but the mechanisms are poorly understood [5]. Inflammation is considered as a very early event in OA perhaps induced by joint trauma affecting chondrocytes in the cartilage and synovial cells (fibroblasts and macrophages) to produce cytokines as interleukin-1-beta (IL-1 $\beta$ ) and tumoral necrosis factoralpha (TNF- $\alpha$ ), and other signaling molecules as proteoglycans to switch to or increase catabolic processes [6]. Obesity has been described as a risk factor for OA by increased mechanical load factors and degenerative knee pain. The mechanisms between obesity and OA are not completly understood but, it has been found the release of fat molecules that can affect the processes in the joint, including adipokines as visfatin and leptin, perhaps affecting the inflammatory response $[7,9]$. Malalignment of the knee joint plays an important role in the development of early osteoarthritis changing the center of pressure of articular cartilage and subchondral bone. Varus or valgus malalignment of the lower extremity results in an abnormal load distribution across the medial and lateral tibiofemoral compartment and being increased in patients with knee osteoarthritis and is increased in patients with overweight. However, studies examining the relationship between malalignment and early knee osteoarthritis have produced conflicting results. The association between malalignment and OA changes is based on radiographic changes mainly and different multicenter OA studies [10-12]. Meniscus is an important tissue in the system of the knee. It is function is the load transmission and absortion shock. Complete or partial loss of meniscal tissue alters the biomechanical and biological of the knee joint modifying the pattern of load distribution and the instability of the knee. Meniscal narrowing, cartilage loss and chondral lesions increase the risk of secondary OA with cartilage degeneration. This secondary $\mathrm{OA}$ is associated to chondral damage, ligamentous instability, and malalignment with reduction in the shock absorption capacity of the knee [13-15]. Extrussion has been associated with articular changes according to their depth into partial-thickness and full-thickens defects. Partial-thickness lesions are considered less symptomatic with little evidence of progression on osteoarthritis. Full-thickness chondral and osteochondral lesions frequently cause symptoms, and they are considered to predispose to 
premature osteoarthritis [16]. Osteochondritis dissecans studies have demonstrated knee joint dysfunction and high prevalence of osteoarthritic change after fragment removal and all the studies take in account the limitation of a small defect size from 1.5 to $4.0 \mathrm{~cm}^{2}$ as well the zone and the location of the defect in the cartilage $[17,18]$. The anterior cruciate ligament (ACL) is the knee ligament most common disrupted. ACL lesion frequently is associated to other ligamentous structures like, menisci, the articular cartilage or subchondral plate $[19,20]$.

\section{Articular cartilage homeostasis}

Articular cartilage is composed of four distinct regions and they differ in their collagen fibril orientation: (a) the superficial or tangential zone $(200 \mu \mathrm{m})$, (b) the middle or transitional zone, (c) the deep or radial zone and (d) the calcified cartilage zone. The superficial zone is composed of thin collagen fibrils in tangential array parallel to surface with a high concentration of decorin and lubricin and a low concentration of aggrecan. The middle zone is composed thicker collagen fibrils more random organized. The deep zone is composed the collagen bundles thickest and arranged in a radial fashion, orthogonal to the surface, and the calcified cartilage zone, located above subchondral bone and the tidemark that persists after growth plate closure and is composed of matrix vesicles, vascularization and innervation from the subchondral bone. The collagen type in the calcified zone surrounding the cells is type $\mathrm{X}$ as in the hypertrofic zone of the growth plate [21, 22], [23]. From the superficial to the deep zone, cell density progressively decreases. The chondrocytes in the superficial zone are small and flattened. The chondrocytes in the middle zone are rounded, and the deep zone chondrocytes are grouped in columns or clusters and they are larger and express markers of the hypertrophy as well. Differences in expression of zonal subpopulations may determine the zonal differences in matrix composition and in the mechanical environment [24, 25].

Chondrocytes live at low oxygen tension within the cartilage matrix, ranging from $10 \%$ at the surface to less than $1 \%$ in the deep zones. In vitro, chondrocytes adapt to low oxygen tensions by up-regulating hypoxia-inducible factor-1-alpha (HIF-1 $\alpha)$, which stimulate expression of glucose transport via constitutive glucose transporter proteins (GLUTs) and angiogenic factors such as vascular endothelial growth factor (VEGF) as well as a number of genes associated with cartilage anabolism and chondrocyte differentiation [26, 27].

It is no clear how chondrocytes maintain their ECM under normal conditions since they lack access to the vascular system but gene expression and protein synthesis may be activated by injury. The aging may affect the properties of normal cartilage by altering the content, composition and structural organization of collagen and proteoglycans. The normal function of the articular cartilage within the joint is to be elastic and have high tensile strength and these properties depend on the extracellular matrix [28]. The chondrocytes produce, in appropriate amounts, this ECM that consist of structural macromolecules of type II collagen fibers, proteoglycans, non-collagenous proteins and glycoproteins, organized into a highly ordered molecular framework. The collagen matrix gives cartilage its form and tensile strength. Proteoglycans and non-collagenous proteins bind to the collagenous network and help to 
stabilize the matrix framework and bind the chondrocytes to the macromolecules of the network. The matrix protects the cells from injury due to normal use of the joint, determines the types and concentrations of molecules that reach the cells and helps to maintain the chondrocyte phenotype $[29,30]$.

The ECM surrounding the chondrocytes has been divided into zones depending on their distance from the cell. The pericellular matrix is localized immediately around the cell, the territorial matrix is next to pericellular matrix and the most distance is the interterritorial matrix. Each matrix zone is characterized by different types of collagens as shown in figure 1 .

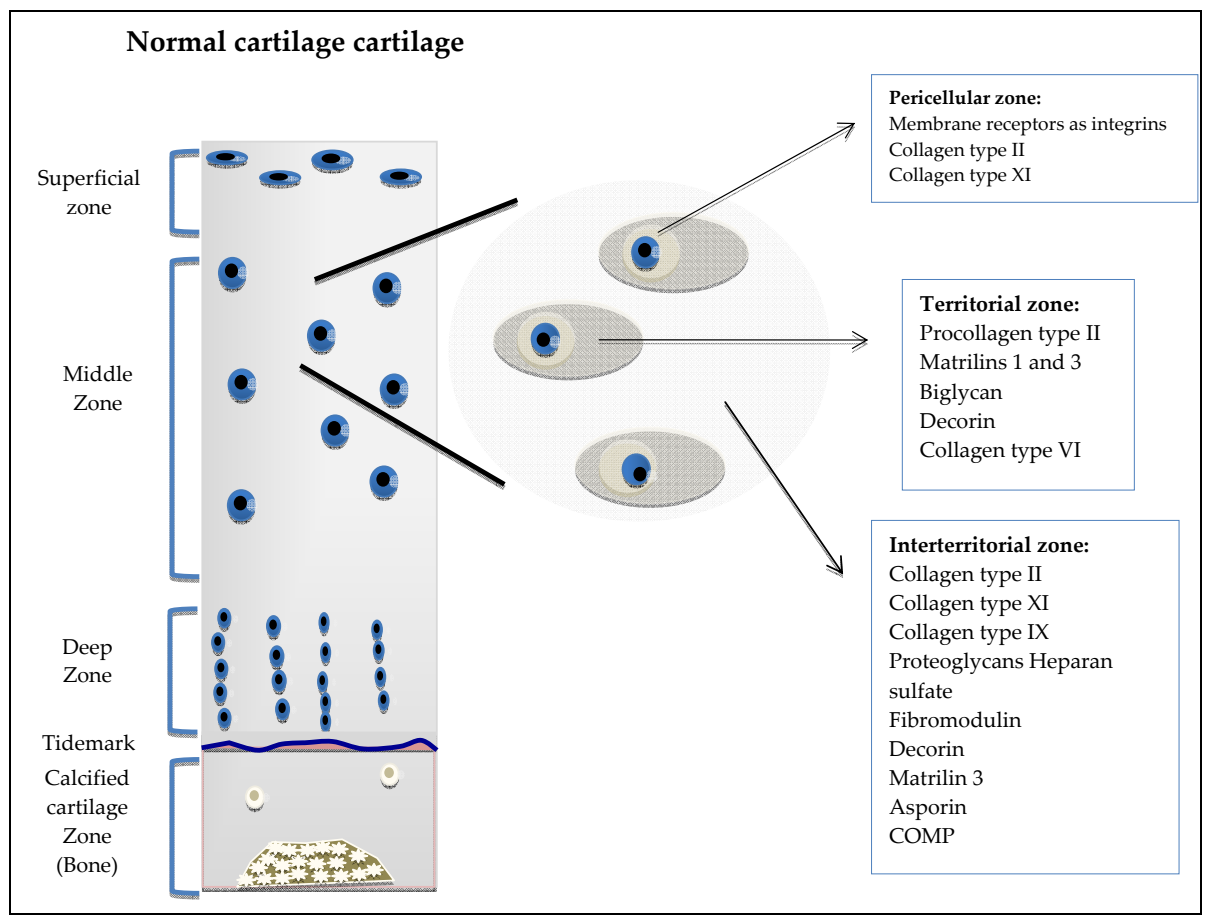

Figure 1. The organization of normal articular cartilage. The organization of chondrocytes is divided in superficial, middle or transitional, deep or radial and calcified cartilage zones with a boundary or tidemark between the first three zones and the calcified zone. The extracellular matrix is divided depending the distance from the chondrocytes. The pericellular zone is the matrix surrounding immediately the chondrocytes. The territorial zone is the next to pericellular zone and the interterritorial zone is the most distant. Every zone has specific characteristics related with the shape of the chondrocyte as well the activity and the expression of different molecules by the cell.

The pericellular matrix is a region surrounding chondrocytes in the articular cartilage where diverse molecules as growth factors have interaction with the receptors expressed on the membrane cell of chondrocyte. This region is rich in proteoglycans as aggrecan, hyaluronan and decorin. Type II, VI and IX are collagen most concentrated in the pericellular network of thin fibrils as fibronectin. Type VI collagen forms part of the matrix immediately surrounding 
the chondrocytes and may help them to attach to the macromolecular framework of the matrix. This pericellular matrix enclosed cells has been termed chondron. The territorial zone contains type VI collagen microfibrils but little or no fibrillar collagen. The interterritorial cartilage matrix is composed of a collagen type II, type XI collagen and type IX collagen integrated in the fibril surface with the non-collagen domain, permitting association with other matrix components and retention of proteoglycans. These collagens give to the cartilage form, tensile stiffness and strength [31-33].

Cartilage contains a variety of proteoglycans that are essential for its normal function. These include aggrecan, decorin, biglycan, fibromodulin and lumican each proteoglycan has several functions determined. The proteoglycans are very important for protecting the collagen network. Other non-collagen molecules as the matrilins and cartilage oligomeric protein $(\mathrm{COMP})$ are also present in the matrix. COMP acts as a catalyst in collagen fibrillogenesis, and interactions between type IX collagen and COMP or matrilin-3 are essential for proper formation and maintenance of the articular cartilage matrix. Perlecan enhances fibril formation, and collagen VI microfibrils connect to collagen II and aggrecan via complexes of matrilin-1 and biglycan or decorin [34].

Throughout life, the cartilage undergoes continual internal remodeling and the chondrocytes replace matrix macromolecules lost through degradation. Therefore normal matrix turnover depends on the ability of chondrocytes to detect alterations in the macromolecular composition and organization of the matrix, including the presence of degraded molecules, and to respond by synthesizing appropriate types and amounts of new molecules. In addition, the matrix acts as a signal transducer for the cells. Loading of the tissue due to use of the joint creates mechanical, electrical, and physicochemical signals that help to direct the synthetic and degradative activity of chondrocytes [22, 35].

\section{Extracellular matrix and cell signaling}

Chondrocytes respond to the mechanical and biochemical changes in ECM through signaling events by various cell surface growth factor receptors and adhesion molecules. ECM proteins can determine the cell behavior, polarity, migration, differentiation, proliferation and survival by communicating with the intracellular cytoskeleton and transmission of growth factor signals. Integrins and proteoglycans are the major ECM adhesion receptors, which cooperate in signaling events, determining the signaling events, and thus the cell function [36].

Integrins are heterodimeric transmembrane receptors formed of eighteen $\alpha$ subunits and eight $\beta$ subunits and they are non-covalently assembled into 24 combinations. The integrin dimers bind to different ECM molecules with overlapping binding affinities determining expression patterns and the downstream signaling events in the cell. Integrins respond specifically to the molecular composition and physical properties of the ECM and integrate both mechanical and chemical signals through direct association with the cytoskeleton. Integrins recognize and bind to the Arg-Gly-Asp (RGD) motif that they are attachment sites for integrin mediated cell adhesion. It has been demonstrated that high density of 
RGD motifs allows a precise spatial distribution pattern of integrins for specific cellular response among ligand molecules [36, 37].

Integrins can activate several signaling pathways independently and frequently they act synergistically with other growth factor receptors as insulin receptor, type 1 insulin-like growth factor receptor, VEGF receptor, TGF-b receptor, platelet-derived growth factor-b (PDGF-b) receptor and epidermal growth factor (EGF) receptor $[37,38]$.

\subsection{Role of proteoglycans in signal regulation}

The heparan sulfate proteoglycans (HSPGs) contribute to the organization of the matrix by binding to the many core matrix molecules via HS chains as laminin, fibronectin and collagen. The chondroitin sulphate proteoglycans (CSPGs) as aggrecan, versican, brevican and the small, leucine-rich proteoglycans such as decorin and biglycan also bind to and regulate a number of growth factors, such as members of the TGF family. The hyaluronic acid is a glycosaminoglycan synthesized on the cell surface and is responsible for the gel-like consistency of cartilage by its hydroscopic properties [36, 39].

\subsection{Remodelation and degradation of ECM}

During normal or pathologic physiology of the cartilage, the ECM must be remodeling and degraded to allow the chondrocytes for processing and deposition of new matrix by specific proteases. There are two well-known families of proteases that are involved in the biology of the ECM, the matrix metalloproteinase (MMP) and the desintegrins and metalloproteinases with thrombospondin motif (ADAMTS) families. The MMP-13 is involved in the cleavage of fibromodulin and type IX collagen and is present and active in the pathological process of cartilage as OA and rheumatoid arthritis. The aggrecanases family's ADAMTS-4 and ADAMTS-5 play an important role in cartilage damage during early OA which cleavage the glycosaminoglycans chains that are the key contributors to the maintenance of the charge density, the osmotic environment and water retain important characteristics of the mechanical properties of the cartilage $[40,41]$.

\section{Alterations of the ECM in the skeletal tissue: Injuries and pathologies}

The extracellular matrix has structural and functional relevance, it's a highly organized and assembled macromolecular structure, also provide cellular adhesion environments, activation and inactivation of growth factors and regulatory cytokines. The proteolytic processing of ECM components, results in the production of fragments with biological effects on migration, proliferation and cellular organization.

When any component of the ECM has a disorder, could generate chondrodysplasia, it means alterations in the development and growth of cartilage. Chondrodysplasias are caused by various mutations in genes involved in cartilage development and finally in the formation and growth of the long bones. These mutations also often alter the formation of other tissues. 
Achondrogenesis type II, is a chondrodysplasia classified as collagenopathy type II. In this family are located several chondrodysplasia caused by mutations in the gene for collagen II, which is the most abundant protein in cartilage [42]. These dysplasias are, achondrogenesis type II, hypochondrogenesis, congenital espondiloepiphysial dysplasia and Kniest dysplasia, among others. Collagen II is a homotrimer (three identical chains encoded by the COL2A1 gene located on chromosome 12. This collagen is mainly found in the hyaline cartilage and vitreous humor, so its deficiency is associated with abnormalities of the spine, of the epiphysis and eye problems. Despite their differences these dysplasias share clinical and radiological manifestations, so the axial skeleton is affected more than the limbs, cleft palate, myopia and retinal degeneration [43].

Furthermore, other disorders of matrix components such as collagen IX and XI, which interact with the collagen II to form supramolecular structures, are closely related phenomena.

It is found that the Osteogenesis Imperfecta (OI) is caused by molecular defects of collagen type I[44] and metaphyseal chondrodysplasia Schmid type is caused by errors in collagen type $\mathrm{X}$ biosynthesis [45], the latter is characterized by alterations in vertebrae and in the metaphysis of long bones, also show reduction of the area of reserve cartilage in growth plate and in the articular cartilage, alters the contents of bone and there is an atypical distribution of the matrix components of the growth plate.

The cartilage oligomeric matrix protein (COMP) is a member trombospondins family, and its alteration causes pseudoachondroplasia, this disorder shows short limbs and lax ligaments [46], the growth plate is shorter and the area of hypertrophic cartilage is reduced.

Cartilage needs molecular signals for development and maintenance, such as growth factors, which in many cases are regulating the synthesis of the ECM, and may be found active or latent in the extracellular matrix. Bone morphogenetic proteins (BMPs), transforming growth factor beta (TGF- $\beta$ ), growth and differentiation factor 5 (GDF-5), are signals related to the development and growth of cartilage, alterations in these molecules cause some malformations, such as the brachypodism (short limbs) [47].

Cartilage matrix is rich in sulfated proteoglycans and the gene encoding for sulfate transporter called DTDST (Dystrophic Dysplasia Sulfate Transporter) in patients with dystrophic dysplasia was found mutations in this gene, and shown to be deficient cartilage sulfating [48].

Campomelic dysplasia is a rare disease associated with $\mathrm{XY}$ individuals who possess varying degrees of sex reversal. SOX-9 is a transcription factor structurally related to the gene SRY (sexdetermining region Y) required for testicular development. However, SOX-9 also directly regulates the gene for type II collagen, the main molecule of the cartilage matrix and therefore of chondrocyte differentiation $[49,50,51]$.

The inactivation of the gene coding for the mouse gelatinase $B$, defined the mechanism that controls the final step of the chondrocyte maturation [52]. Gelatinase B is an enzyme present in the extracellular matrix of cartilage and its activity is related to the control of apoptosis of hypertrophic chondrocytes and the vascular tissue. This study hypothesized the existence of chondroclast, these cells of myeloid origin express gelatinase-B and are located in the cartilage/ bone region and resorb cartilage matrix. 
Based on the above is to emphasize the importance of the extracellular matrix as a modulator of cellular differentiation of chondrocytes, the extracellular components correlate with the differentiation state. That is, collagen I is present at early stages of differentiation and maturation, in mesenchyme and perichondrium; collagen II is on mature cartilage and collagen $X$ is exclusive of hypertrophic cartilage also collagen type I are expressed in terminal stages of chondrocytes [53].

The ECM not only serves as a binder that gives form to tissues in addition to their structural role has physiological functions. The chondrocytes are in the array a series of signals that allows them to gain some cell shape and organization of the cytoskeletal network. Cell morphology that can modulate many physiological functions such as proliferation, differentiation, cell death and gene expression. This transmembrane receptor-mediated would be able to receive the extracellular signal from the ECM and transduce the signal into the cell, triggering a response by the chondrocyte differentiation [54].

Integrins are transmembrane receptor consisting of one $\alpha$ subunit and a $\beta$, are only functional to form the $\alpha$ - $\beta$ heterodimer on the cell membrane. $\beta 1$ family of integrins are major receptors of ECM molecules and have the ability to allow cell adhesion and simultaneously issuing an intracellular signal to which the cell responds in different ways, as also interact with integrins the cytoskeleton and molecules involved in signal transduction.

It has been shown that integrins interaction with extracellular matrix molecules affects cytoskeleton organization, proliferation, differentiation and gene expression in fibroblasts and epithelial cells.

In addition we have studied the survival and differentiation of chondrocytes, including the deposit in the interstitial matrix of collagen type $X$ could be mediated by integrins [55]. Inhibition of integrin $b 1$ subunit with a neutralizing antibody blocks the deposition of collagen $\mathrm{X}$ in the interstitial matrix and growth of the breastbone is decreased. Moreover, the chondrocytes are significantly smaller, show a disorganization of the actin cytoskeleton and show increased apoptosis.

There is also evidence that blocking the $\beta 1$ subunit of integrins in an in vitro model of differentiation of cartilage inhibits cartilage nodule formation and the synthesis of collagen type II [56].

However, the study of the role of these receptors in the process of chondrocyte differentiation is not yet well established, but it would be of significant importance in determining the relationship of the extracellular matrix to the chondrocyte.

\subsection{The extracellular matrix and chondrocyte differentiation in osteoarthritis}

Articular cartilage mineralization frequently accompanies and complicates osteoarthritis and aging. Several works has demonstrated that certain features of growth cartilage development are shared in degenerative cartilage. These include chondrocyte proliferation, hypertrophy, matrix mineralization and apoptosis. Development of growth plate is regulated by growth factors signaling and cellular interactions with the extracellular matrix (ECM). Parathyroid 
hormone related protein (PthrP) and Indian Hedgehog (Ihh) are central mediators of endochondral development; PthrP is abundant in synovial fluid of osteoarthritic patient but Ihh expression is diminish in OA cartilage, Fgf-18 is a regulator of chondrocyte proliferation and its intra-synovial application in OA rat results in cartilage generation. Also, Wnt signaling plays an important role in chondrocyte differentiation in growth plate, Wnt-5a promotes chondrocyte prehypertrophy and inhibits chondrocyte hypertrophy unlike Wnt- 4 that induces chondrocyte hypertrophy and increases its expression in early stage of osteoarthritis. On the other hand, is pronounced imbalance of cartilage matrix turnover in osteoarthritic cartilage, and results in mayor deposition of collagen type I and X, reduced expression of collagen type II. Thus, the rate of chondrocyte hypertrophy is higher on growth plate and OA articular cartilage than healthy articular cartilage, it recap the signaling in cartilage growth plate. But, although articular and growth plate cartilages share several features, there are one important difference, the rate of cartilage hypertrophy. What is the signal that makes the difference? In the ECM we could find some elements to answer this question.

\subsubsection{Alterations in the extracellular matrix of articular cartilage during $O A$}

Traditionally it has been thought that osteoarthritis is a disease of wear or tears consequence of articular cartilage due to aging or following injury. The limited regenerative capacity of cartilage cannot reverse its destruction, it is sometimes triggered by an inflammatory response from the synovial, inflammation occurs when the condition is called osteoarthritis [57]. Until recent years genetic mutations were excluded as a risk factor or predisposition to osteoarthritis. The first genes identified to OA encode components of the extracellular matrix, such as Collagen COL2A1, COL9A2 and COL11A2, which were studied in transgenic mouse models [58]. It has been found that the substitution of glycine destabilizes the triple helix structure of collagen type II making it more susceptible to degradation by MMP-13 [59]. Other ECM molecules related to OA are ADAMTS- 4 and ADAMTS- 5 enzymes which degrade aggrecan, the most abundant proteoglycan in articular cartilage [60]. When aggrecan is degraded, the collagen II is exposed to the DDR-2 enzyme which is able to degrade it [61]. The alteration of the ECM of articular cartilage in the first instance causes cell proliferation and the formation of fibrous tissue that forms a scar in response to injury, there are produced growth factors such as TGF- $\beta$ could promote chondrocyte hypertrophy, so that recapitulates OA cartilage differentiation mechanisms of the growth plate to form ultimately bone nodules at the edges of articular cartilage called osteophytes [62]. Clearly the importance of ECM in the differentiation of articular cartilage, but there are various growth factors and transcription factors that regulate the maturation and proliferation of chondrocytes in articular cartilage and cartilage growth plate, which also control the expression of many of the components of the ECM, and also direct the skeletal morphogenesis. Genes has recently been determined as Smad-3, Dkk, Wnt4, Mig-6 etc [63- 66], OA generated in murine models, these molecules regulate different cellular processes such as cell proliferation, cell differentiation, cell death, degradation and synthesis of ECM. We can group the molecules according to the governing process: Chondrogenesis, Proliferation, Differentiation and Cell Death. Many of these molecules can be good genetic markers of predisposition to OA, and are fundamental to how to design a strategy for articular cartilage repair. 


\subsubsection{Differentiation of articular cartilage chondrocyte}

Although exists different types of cartilage, they are very similar but have different functions. Articular cartilage and cartilage growth plate are good examples. In general, the molecular mechanisms of chondrocyte differentiation in both cartilages are equivalent. However, for the function of synovial joints is essential that chondrocytes maintenance in prehypertrophic state differentiation, while the longitudinal growth of bone depends on the proliferation and differentiation of chondrocytes in the growth plate to the hypertrophy and bone formation $[67,68]$. We can even talk about a model that relates the structure and function of cartilage based on histological and functional differences of both cartilages. Both in the cartilage growth plate and in articular cartilage chondrocytes can be found at various stages of differentiation, but the organization and activity of chondrocytes differ in each stage of both cartilage.

In the growth plate chondrocytes reserves represent an immature state and are organized in tiny rows of small round cells, embedded in an abundant extracellular matrix rich in collagen type II and aggrecan, proliferating chondrocytes are stacked as "coins" several rows forming compact occupying a large area of the growth plate, the first rows are more proliferation activity than the rows deep; prehypertrofic chondrocytes (mature) are larger cells that have exited the cell cycle and express Ihh, a key molecule in cartilage differentiation, these cells secrete and accumulate a large amount of carbohydrates and finally the hypertrophic chondrocytes are cells of highest volume and high alkaline phosphatase activity, the ECM is mainly composed of collagen type $X$ and begins to calcify, some cells degenerate and die by apoptosis leaving the spaces occupied to consolidate osteoblasts and bone tissue. This process is known as endochondral ossification which regulates the growth of bone in terms of cartilage differentiation. It is noteworthy that an important signaling center in this process is the perichondrium, which are very small and flattened cells surrounding the cartilage and expressed PTHrP [69] and Fgf-18 [70], which respectively induce and inhibit the proliferation of chondrocytes, the receiver PPR and PTHrP [71] is expressed in the upper rows, whereas the Fgf-18 receptor and FGF-R3 is found in the deeper cell layers of proliferating chondrocytes. Patch is Ihh receptor and is expressed in the perichondrium, so that Ihh induces the expression of PTHrP and this in turn induces proliferation and expression of Ihh in the growth plate. This regulatory loop promotes the longitudinal growth of the mold of cartilage, but it is necessary that the mold is rigid. For this, the FGF18 inhibits the proliferation of cartilage to regulate expression of Ihh and this result in the differentiation of chondrocyte hypertrophy up. This signaling cascade also occurs during the formation of joint cartilage, where bone formation is more limited as in the secondary ossification centers.

Articular cartilage has apparently different stages of differentiation of chondrocytes, only that which corresponds to the resting chondrocytes have important differences in the composition of the ECM, as the presence of lubricin, the Collagen type IIa the aggrecan, CD44, ASC, [72, 73] these cells are most abundant in the articular cartilage cells for proliferation area are not organized in rows and have very low proliferation rate, making them more similar to the prehypertrophic cartilage, as the rate of is very slow maturation, hypertrophic chondrocytes 
make up a small area of just one or two cell lines the border between cartilage and bone, known as "water mark" (tide mark).

\subsection{Endochondral ossification during skeletal development and OA}

The joints that separate from each other skeletal elements serve as important signaling centers during skeletal development, and regulate the proliferation and maturation of chondrocytes. It is well known that chondrocyte maturation is crucial for endochondral ossification and to define the final size of each skeletal element. In the end, the processes of the formation of joints and cartilage differentiation of skeletal elements are strongly related. The limb skeletal elements are formed by endochondral ossification, the process begins with the aggregation of mesenchymal cells that form the pre-cartilaginous condensation, this condensation increases the proliferation of chondrocytes and forms a "bar" initial cartilage [74]. It has been proposed that the first step for the formation of the joint is that it inhibits differentiation of prehypertrofic chondrocytes in cells located in the region of the joint prospecting, outside the influence of signals that promote maturation of the cartilage, while neighboring cells continue their differentiation process to form bone hypertrophy and subsequently by endochondral ossification, so contributing to the formation of adjacent skeletal elements [75]. Cells suspected joint region form the interzone, characterized by a highly packed region of flattened cells, these cells produce other types of collagen and collagen type I and III, unlike chondrocytes that produce collagen type II. The interzone also expressed molecules such as Wnt-9a [76] and Bmp antagonists like noggin [77], which remain the property of these cells not chondrogenic. Some cell adhesion molecules such as integrin $\alpha 5 \beta 1$ also regulate the formation of joints by controlling the differentiation of chondrocytes [78], whereas other signaling molecules that are expressed in the interzone as Wnt-4, Fgf-18, Gdf (5, 6 and 7) and several members of the Bmp, promote growth and differentiation of adjacent cartilaginous elements [79]. It is likely that different cell types present in a mature synovial joint, including synovial cells, articular chondrocytes and permanent joint capsule cells originate in the interzone. Permanent articular chondrocytes originating from the interzone, are very similar to chondrocytes in the growth plate, and although both cell types are hyaline cartilage and functions have important differences. The most important difference is that articular chondrocytes decrease its maturation toward hypertrophy of chondrocytes unlike the growth plate which we observed a wide region of hypertrophic chondrocytes, as this process allows for the ossification and growth of long bones. Hypertrophic chondrocytes are the highest volume and produce a very specific extracellular matrix rich in collagen type X. The hypertrophy of chondrocytes is followed by apoptosis, the invasion of blood vessels, osteoclasts and other mesenchymal cells from the perichondrium and production of bone matrix. Therefore, the size and fine structure of the long bones depends on the coordinated regulation of proliferation, maturation and hypertrophy of chondrocytes in response to many extracellular signals. The protein Indian hedgehog (Ihh) and peptide related to Thyroid Hormone (PTHrP) play a critical role in these processes, Ihh is pro- 
duced by prehypertrophic chondrocytes and induces the expression of PTHrP in the perichondrium which in turn regulates the rate of chondrocytes which exit the cell cycle and continue to hypertrophy [80]. Ihh also stimulates proliferation of chondrocytes and controls the differentiation of mesenchymal cells into osteoblasts in the collar bone. Thus, when the chondrocytes stop expressing Ihh activates the expression of Runx-2 and Runx-3 [81], some transcription factors required for hypertrophy of chondrocytes and differentiation of osteoblasts. On the contrary, in particular FGF-18 [82] expressed in the perichondrium and through its receptor Fgf-R3 expressed in cartilage prehypertrofic cartilage negatively regulates cell proliferation and promotes the hypertrophy of chondrocytes, the constitutive activation of FGFR3 results in dwarfism [83] and may inhibit the formation of joints, this confirms the idea that proliferating chondrocytes may have two possible destinations, become pre-articular chondrocytes or prehypertrophic chondrocytes.

\subsection{Control of chondrocyte differentiation and two destinations, Ihh vs Wnt signaling and its role in $\mathrm{OA}$}

During the formation of the skeleton some chondrocytes are involved in the growth of long bones and ossification. At this early stage, the GDF-5 signaling is essential for the formation of joints and articular cartilage [84, 85], its expression is delimited in the interzone and begins just before forming the joints, on the other hand, the Bmp-7 is important for the chondrocyte maturation and bone formation and is expressed in the perichondrium of the skeletal elements in formation and growth [86], but not expressed in the perichondrium of the developing cartilage. Although the induction of the joint is initiated by the expression of Wnt-9a in the interzone and the interzone chondrocytes lose their phenotype [76], GDF-5 signaling is essential for the joint and articular cartilage formation. Ihh is another important molecule for skeletal development, Ihh inhibits Wnt-9a expression and is maintained in skeletal growth and endochondral ossification, as when it reaches a certain size decreases the expression of Ihh and thereby activates the expression of Wnt patway induces hypertrophy of chondrocytes and bone formation [87]. It is noteworthy that during the OA Wnt signaling is overactivated [65] and GDF-5 is downregulated, which suggests a recapitulation of endochondral ossification during OA. Furthermore, when the receptor Bmp-RIA is inactivated in mouse generated phenotypes similar to human osteoarthritis and when activated the Wnt pathway by blocking antagonist Dkk [64], reverse the process of articular cartilage destruction and endochondral ossification, this suggests that these pathways permit the maintenance of adult articular cartilage.

\subsection{Proliferation, hypertrophy and cell death are activated during OA}

Not only in the embryonic stages imbalance of proliferative signals and bring important consequences hypertrophy in articular cartilage, osteoarthritis is a striking example of this imbalance of signals. There are animal models that recapitulate this degenerative joint disease, as in the case of the mutant mice of Smad-3 [63], a molecule that transduces the TGF- $\beta$ signal. Molecular analysis of these mice shows ectopic expression of type $X$ collagen in the articular 
cartilage and increased hypertrophy of chondrocytes; this shows the TGF- $\beta$ as an inhibitor of differentiation of articular chondrocytes. Similarly, the cancellation of Mig- 6 in mice results in early degeneration of joints [66], as evidenced by degradation of articular cartilage, fibrous tissue formation and growth of osteophytes. It is well known that articular cartilage injuries may result in osteoarthritis, fibrous tissue formation is an immediate healing response to a traumatic injury, and the healing is often promoted by TGF- $\beta$, which in turn could induce osteophyte formation that recapitulates chondrogenesis and endochondral ossification in adult articular cartilage.

\subsection{Why not articular cartilage regenerate}

During development are constantly chondrocytes proliferation and differentiation, thus skeletal elements grow in length and ossify, as mentioned earlier, articular cartilage chondrocytes have a low rate of proliferation and differentiation, this makes them different and allows articular cartilage is kept almost throughout life. What keeps the ever-growing cartilage during development is the molecular signals that modulate the rate of growth and differentiation, these signals are regulated by the perichondrium. The perichondrium has progenitor cells that are very useful for cartilage repair, its similar to bone, the periosteum is important for bone repair, such as fractures. While the perichondrium is maintained until adult stages, the perichondrium is disappearing from the stage young individuals, which is why the low capacity of regeneration of cartilage [88].

\section{Current methods for cartilage tissue engineering and future perspectives}

\subsection{Autologous chondrocytes for tissue regeneration}

The hyaline articular cartilage is a highly specialized tissue and its main function is to protect the bone from friction in the joints $[89,90]$, once articular cartilage is damaged their ability to self-repair and regeneration is limited as mentioned above. Cartilage injuries are mainly associated with anterior cruciate ligament, patellar dislocation, followed by a meniscectomy [91]. Osteochondral lesions of the knee are determined mainly by arthroscopic knee surgery $[92,93]$, which is seen mainly in traumatic injuries, together with abnormal stresses on the knee.

To determine the treatment for the repair and regeneration of articular cartilage injury, have developed different techniques, the techniques described are focused on the repair, reconstruction or regeneration of tissue. The repair methods (drilling or microfracture) support the formation of new tissue fibrocartilaginous $[94,95]$ while the reconstructive method seeks to fill the defect with allografts (OATS) combining with miniarthrotomy arthroscopy. And finally the regenerative methods that rely on bioengineering techniques to develop a hyaline cartilage tissue graft or autologous chondrocyte cell matrices (Table1). 


\begin{tabular}{|c|c|c|c|}
\hline Ref. & Method & Technique & Results \\
\hline [96] & \multirow{3}{*}{$\begin{array}{l}\text { Drilling with } \\
\text { lavage and } \\
\text { debridement }\end{array}$} & \multicolumn{2}{|l|}{ Removal of osteophytes and knee abrasion } \\
\hline [97] & & Perform subchondral drilling of the lamina & Tissue repair and pain relief \\
\hline [98] & & Elimination of subchondral lamina & $\begin{array}{l}\text { Significant symptomatic } \\
\text { improvementin } 75 \% \text { of patients }\end{array}$ \\
\hline $\begin{array}{l}{[99,} \\
100]\end{array}$ & Microfracture & $\begin{array}{l}\text { Perforation of the subchondral lamina by arthroscopy, it } \\
\text { promotes the release of mesenchymal cells in the lesion, forming } \\
\text { a plug of tissue }\end{array}$ & $\begin{array}{l}\text { Avoids necrosis associated with } \\
\text { the use of the drill and preserves } \\
\text { the subchondral surface. } \\
\text { The results observed in the } \\
\text { medium term, mainly in young } \\
\text { patients, about } 20 \% \text { of patients } \\
\text { do not reach after five years. }\end{array}$ \\
\hline $\begin{array}{l}{[101-} \\
104]\end{array}$ & $\begin{array}{l}\text { Chondrogenesis } \\
\text { induced } \\
\text { stimulation of } \\
\text { bone marrow } \\
\text { (AMIC) }\end{array}$ & $\begin{array}{l}\text { Followed by a micro abrasion bill and placing a collagen scaffold } \\
\text { on the defect, inducing the formation of fibrocartilage by } \\
\text { migrating mesenchymal cells and the expression of cytokines and } \\
\text { tissue repair }\end{array}$ & $\begin{array}{l}\text { Stimulation of bone marrow has } \\
\text { limited mechanical strength and } \\
\text { may even degrade the cartilage is } \\
\text { repaired with fibrous tissue or } \\
\text { fibrocartilage so that there is } \\
\text { tissue degeneration. }\end{array}$ \\
\hline $\begin{array}{l}{[105-} \\
107]\end{array}$ & $\begin{array}{l}\text { Mosaicplastyandt } \\
\text { ransplantosteoch } \\
\text { ondral allograft }\end{array}$ & $\begin{array}{l}\text { Is based on obtaining osteochondral cylinder obtained from areas } \\
\text { of low load from the distal femur, which are grafted into the } \\
\text { defect }\end{array}$ & $\begin{array}{l}\text { The results are limited in large } \\
\text { lesions due to donor site } \\
\text { morbidity and healing of the } \\
\text { seams in the recipient }\end{array}$ \\
\hline $\begin{array}{l}{[108-} \\
110]\end{array}$ & $\begin{array}{l}\text { Autologous } \\
\text { chondrocyte } \\
\text { implantation }\end{array}$ & $\begin{array}{l}1^{\text {st }} \text { Generation: In this technique, cartilage cells are injected under } \\
\text { a cover of periosteum is sutured into the defect. } \\
2^{\text {nd }} \text { Generation: is replaced cover membrane or periosteum } \\
\text { biomaterials, which can have different components }\end{array}$ & $\begin{array}{l}\text { It has been reported good results } \\
\text { in most patients after 10-20 years } \\
\text { after implantation. } \\
\text { In the second generation } \\
\text { transplants with areas of } \\
\text { fibrocartilage, possibly because of } \\
\text { low cell density and lack of } \\
\text { proliferative capacity. This } \\
\text { technique replaces healthy } \\
\text { cartilage to regularize the defect. }\end{array}$ \\
\hline [111] & $\begin{array}{l}\text { Autologous } \\
\text { chondrocyte } \\
\text { implantation } \\
\text { induces } \\
\text { extracellular } \\
\text { matrix }\end{array}$ & $\begin{array}{l}3^{\text {rd }} \text { Generation: In this technique, autologous chondrocytes } \\
\text { cultured on a three-dimensional artificial scaffold }\end{array}$ & $\begin{array}{l}\text { Has been used in the past two } \\
\text { decades, with this type of } \\
\text { membranes hypertrophy is } \\
\text { reduced by } 5 \% \text {, after } 3 \text { to } 6 \\
\text { months membrane is reabsorbed. }\end{array}$ \\
\hline
\end{tabular}

Table 1. Cartilage repair techniques 
Each of these procedures is associated with improvement of these techniques with the use of biomaterials or with the use of growth factors. In the autologous chondrocyte implantation of the second generation is required arthrotomy so this technique becomes more complicated. In order to facilitate and improve the technique and quality of the tissue repair, has developed a method which has proved more effective and easy to implement in the knee joint $[112,113]$ develop and autologous chondrocyte implantation induced extracellular matrix of the third generation.

\subsection{Description of the technique of autologous chondrocyte implantation induced extracellular matrix (third generation).}

\subsubsection{Obtaining the tissue}

This technique is mainly based on the autologous cultured chondrocytes on a biocompatible three-dimensional scaffold which is subsequently implanted into the defect. As in the technique of autologous chondrocyte implantation of the second generation, it requires a prior arthroscopic surgery where a piece of cartilage obtained from a zone of no load of the knee joint (intercondylar notch or the lateral edge of the trochlea) after obtaining the sample fragment is processed to obtain chondrocytes in culture.

\subsubsection{Implant preparation}

Cartilage fragments are disintegrated mechanically to obtain smallest fragment, is performed subsequent enzymatic digestion to release trapped chondrocytes in the matrix of collagen. Expansion of chondrocytes was performed in 8 weeks. Days before implantation chondrocytes are seeded on a scaffold or membrane [112] Rich in collagen, which is considered a threedimensional extracellular biomaterial consists mainly of collagen I and III, the scaffold contains glycosaminoglycans, proteoglycans and glycoproteins [111, 114, 115] cells are capable of synthesizing a typical matrix of chondrocytes facilitating cell adhesion and influence the morphology, migration and differentiation of cells.

\subsection{Advantages of autologous chondrocyte transplantation induced extracellular matrix (third generation) on the autologous chondrocyte implantation (second generation)}

The main advantages of autologous chondrocyte transplantation induced extracellular matrix (third generation) is that no cell loss is not presented hypertrophic tissue growth, requiring only a second incision is a safe procedure for treatment of injuries symptomatic articular cartilage surgery facilitates reducing the operating time and the need for open surgery compared to traditional surgery for autologous chondrocyte implantation (second generation). While in the second generation technique leads to form hyaline cartilage on the surface showing fibrosis and proliferation of small blood vessels (reactive fibrosis), by the use of periosteum, so that in this case it is advisable the use of membrane collagen 


\section{New proposals for repairing articular cartilage}

In recent years they have sought new strategies for cartilage repair, with technological advances have currently been proposed the use of scaffolding or matrix on which cells can grow. Among the scaffolds used in the clinic (Table 2) are those that are based on collagen, hyaluronic acid and fibrin as these provide a substrate normally found in the structure of native articular cartilage. Collagen is a major extracellular matrix protein, exists to provide strength and stability to the connective tissues. At the clinic is used collagen I-III as scaffolds for growing chondrocytes in order to improve the structural and biological properties of the graft [116, 117] this is used as a sponge, foam, gel and membrane form, all these are subject to enzymatic degradation. Hyaluronic acid is another important component of articular cartilage matrix and is a glycosaminoglycan that is involved in homeostasis $[118,119]$ provides viscoelasticity to synovial fluid, is credited as a lubricant and shock absorbing properties, is essential for the correct structure of proteoglycans in articular cartilage. Between scaffolds containing hyaluronic acid is the Hylaff-11, which is an esterified derivative of hyaluronic acid and is used for growing chondrocytes in three dimensions, has been shown that when using this type of scaffold maintaining the chondrocyte phenotype, so that chondrocytes are capable of producing the proteins and molecules characteristic of a hyaline cartilage [120-122]. Fibrin is a protein involved in blood coagulation, is regarded as a biomaterial for cartilage repair, as can be found in gel form, having an adhesive function that is also biocompatible and biodegradable [123]. However in vivo studies in animals have shown to have low mechanical stability and can also trigger an immune response [124, 125], fibrin because this has only been used clinically to ensure healthy cartilage tissue-engineered the [126-128].

Based on the foregoing and which is being used in the clinic and according to results obtained in patients who have been treated with different biomaterials has been observed that although there is a suitable biomaterial that contributes to the production of extracellular matrix to provide the right conditions for chondrocyte cell differentiation. So it is necessary to propose new biomaterials that help produce extracellular matrix, capable of activating a cascade of signaling that can form a cartilage which has structural properties suitable for tissue repair, as well as having viscoelastic properties and to provide mechanical stability.

\section{Cartilage tissue engineering and low scaffold successful}

Many advances in the field of cartilage tissue engineering have been closely connected to the improved performance of biomaterials. Successful cartilage tissue engineering relies on four specific criteria: (1) cells, (2) signaling molecules, (3) biomaterials, and the (4) mechanical environment. Furthermore, they should be biocompatible, non-toxic, bioresorbable and highly permeable to facilitate mass transport [139].

The use of scaffolds to support replication of chondrocytes for production of cartilage in vitro has been the most common approach for tissue engineering of cartilage, however, despite the 


\begin{tabular}{|c|c|c|c|c|}
\hline Ref. & Biomaterial & Component & $\begin{array}{c}\text { Method of autologous } \\
\text { Chondrocyte transplantation }\end{array}$ & Results \\
\hline $\begin{array}{l}{[126} \\
129- \\
132]\end{array}$ & Carticel & \multirow[t]{2}{*}{ Collagen I-III } & 2nd and 3rd generation & \multirow[t]{2}{*}{$\begin{array}{l}\text { Three-dimensional multi-layer } \\
\text { keeps the chondral phenotype }\end{array}$} \\
\hline [113] & Matricel & & 2nd generation & \\
\hline $\begin{array}{l}{[133,} \\
134]\end{array}$ & $\mathrm{CaReS}^{\circledast}$ & $\begin{array}{l}\text { Collagen I } \\
\text { hydrogel }\end{array}$ & 2nd generation & $\begin{array}{l}\text { It presents a significant functional } \\
\text { improvement as well as acting on } \\
\text { the levels of pain. }\end{array}$ \\
\hline $\begin{array}{l}{[135-} \\
136]\end{array}$ & Hyalograft-C & \multirow{2}{*}{$\begin{array}{l}\text { Hyaluronic } \\
\text { acid }\end{array}$} & 3rd generation & $\begin{array}{l}\text { Maintaining the chondral } \\
\text { phenotype, absence of } \\
\text { inflammatory response, formation } \\
\text { of hyaline cartilage }\end{array}$ \\
\hline [137] & Hyalgan $^{\oplus}$ & & -------------- & $\begin{array}{l}\text { Indicated for the treatment of } \\
\text { osteoarthritis of the knee, } \\
\text { improves mobility and reduces } \\
\text { pain. }\end{array}$ \\
\hline [113] & Tisseel & Fibrin & 3rd generation & $\begin{array}{l}\text { Fibrin is an integral component of } \\
\text { the extracellular matrix induced } \\
\text { chondrocytes, so that the new } \\
\text { cartilage is well integrated into } \\
\text { the underlying subchondral bone. } \\
\text { Moderate application of fibrin }\end{array}$ \\
\hline [138] & Cartipatch & $\begin{array}{l}\text { Alginate } \\
\text { Hydrogel- } \\
\text { agarose }\end{array}$ & ------- & $\begin{array}{l}\text { Hyaline cartilage was observed in } \\
\text { eight of the } 13 \text { patients treated, } \\
\text { clinical improvement at } 2 \text { years of } \\
\text { treatment }\end{array}$ \\
\hline
\end{tabular}

Table 2. Biomaterials most used in the clinic, with different components for the repair of articular cartilage by autologous transplantation method of chondrocytes from second and third generation.

apparent simplicity of cartilage, to our knowledge, tissue engineered cartilage has not been successfully reached so far [140-142].

In theory, a scaffold for tissue engineering should have a three dimensional porous structure forming an interconnected porous network. These structures should be made of biocompatible and biodegradable materials capable to provide mechanical strength, support cells ingrowth, promote cells adhesion, uniform cell spreading, and conserve phenotypes and functional characteristics of transplanted cells [143,144]. Unfortunately, this list of requirements looks too long and hard to accomplish. Probably this is one of the main reasons of why the advances in cartilage engineering have been too slow. But also we should rethink these concepts in order to find shorter and easier pathways to find more efficient and effective tissue engineering methods. 
The vast majority of scaffolds used in tissue engineering are solid sponge-like porous structures that are seeded with cells in a culture media. Analyzing this approach from the basic principles for the design of biomaterials, the biomimetism, easily we can find out that this process lacks of this basic concept. In natural tissues, cells grow in a physiological environment which is more like a gel medium than a porous scaffold, they do not form tissues by populating porous structures, but they do it by creating their own ECM starting from a gel-like environment. Following this line, many researchers are proposing the encapsulation of cells in hydrogels instead of using porous scaffolds, looking to improve the biomimetic environment for cells $[145,146,147,148]$.

Besides biomimetism, sponge-like scaffolds provides only a two dimensional surface for cell attachment, although their structure is $3 \mathrm{D}$, cells attach to the walls of the scafflod, thus changing completely the way they are integrated into natural tissues. On the other hand hydrogels are capable to provide a real 3D environment when cells are seeded (encapsulated) into them [149].

\subsection{Hydrogels for articular cartilage tissue engineering}

Hydrogels are water-swollen, cross-linked polymeric structures [150] that possess unique mechanical and chemical properties that make them very attractive for a variety of biomedical applications; actually there are no other materials capable to display characteristics too close to natural tissues such as Hydrogels. Therefore hydrogels have been considered as a key material in the development of new biomaterials for tissue engineering and artificial organs fabrication.

Their particular properties come from their structure, composed of swollen randomly crosslinked networks of rod-like polymer chains with water filling the interstitial spaces.[151] Water commonly comprises more than $80 \%$ of the total volume. The physical properties of hydrogels are determined by the polymer composition and concentration, the cross-linking density between polymer chains [152], polymerization conditions [153], the addition of hydrophobic monomers which may create regions of more dense coiled or entangled chains, the introduction of composite materials such as rubber or glass, the use of cross-linking agents such as glutaraldehyde, and the use of freeze-thawing procedures to induce partial crystallinity [154].

Hydrogels can be classified by the type of crosslinking: covalently or ionic cross-linked, physical gels, or entangled networks [155]. The two first are the most common gels. Physical gels are formed by non-covalent interactions, such as hydrogen bonding, and hydrophobic interactions [156]. Covalently or ionic cross linked gels are considerably more stable than physical gels and once they are formed they may not be re-melted again.

Hydrogels can be obtained from natural or synthetic polymers. Natural hydrogels come from proteins and polypeptides (commonly collagen and gelatin), polysaccharides (i.e. alginate, agarose, hyaluronic acid, fibrin, chitin and chitosan). On the other hand, synthetic polymers come from man-made materials such as polyester (i.e. poly L-lactic and polyglycolic acid, poly $\varepsilon$-caprolactone, polypropylene fumarate), polyethylene oxide, polyethylene glycol, polyvinyl 
alcohol, polyurethane, polydiol citrates, polyhydroxyethyl methacrylate, and many others polymers [157].

Although hydrogel scaffolding technologies plays a crucial role in cartilage tissue engineering, several studies has been shown low success cartilage tissue repair. They are unable to generate cartilaginous tissues with similar properties to native cartilage [141-142].

There are a number of reasons for scaffolds failure, we summarized some of them:

1. The scaffold architecture should be designed to mimic the depth-dependent heterogeneity of articular cartilage structure or to generate multiphasic scaffolds to promote the simultaneous growth of bone and cartilage with a stable interface for engineering osteochondral tissue.

2. However, manufacturing scaffolds technologies are limited and no optimum architectures have been produce yet.

3. The study of biological cartilage development is still growing.

4. Not enough knowledge about:

5. the role of chondrocyte ECM and their implications during chondrogenesis.

6. the role of adhesion molecules and signaling pathways during chondrogenesis.

7. Culture chondrocytes in vitro and density cells conditions in scaffolds.

8. Dynamic cartilage ECM and their Nanomechanical properties.

9. Chemical variables in cell-scaffolds interactions, among others.

\subsection{Trends in hydrogel-scaffolding cartilage repair}

However towards designing biomimetic native environments cartilage is still a challenge due articular cartilage is intricately organized and heterogeneous tissue. This tissue reveals a highly defined structural organization that can be subdivided into two domains, the cartilage zones and the organization of the extracellular matrix. In that sense the ECM of articular cartilage is a unique environment with complex heterogeneity and spatial conformation very difficult to mimic. One of the most notable variations in this tissue is the spatial organization of collagen network and cells arrangement. [141]. Moreover cartilage presents different morphology, gene expression, matrix spatial array between cultured populations isolated from distinct cartilage zones [142]. However, intensive researches have been focus on the development of an ideal scaffold material with versatile properties that actively contribute to cartilage repair [158]. In that regard, there have been several attempts trying to recreate the different zones in cartilage by different hydrogel fabrication technologies, giving as a result tridimensional homogeneous structures with little resemblance to the native organization in cartilage, so it is necessary to material scientists thinking in others design hydrogel-scaffolding strategies trying to biomimetic hierarchical structures capable to deliver bioactive molecules such as growth factors with an ideal mechanical response and mediated by adhesive molecules in order to have an integration tissue [159]. 
Currently strategies in the design of biomimetic cartilage hydrogels are governed by the use of collagen Type I and derived from porcine small intestine submucosa implants. Although the chondrocytes typically lose their phenotype, the gene expression patterns changed when they are removed from their native environment, so give them a proper environment is necessary to keep its phenotype of chondrocytes in different populations to recreate the zonal organization [160]. In addition, biological trials in vitro be made taking into account the cell density for each zone [161,162].

According with reference [163] concentrations of 12-25 million cells $/ \mathrm{cm}^{2}$ are needed to increase the matrix production and mechanical properties of human adult chondrocytes under static conditions. Nevertheless, material researches are focus on fabrication of three-dimensional artificial arrays in form of hydrogels using macromolecules present in the cartilage interterritorial matrix and trying to mimic the distinct cartilage zonal [160]; however, no substantial data of the formation of cartilage are reported.

Others approaches in cartilage tissue engineering are the use of hydrogel culture employed mesenchymal stem cells (MSCs) and the use of bioreactors in order to provide the necessary biochemical and biomechanical stimulations to enhance chondrogenesis $[164,165]$. Due to the many mentioned limitations related to chondrocyte sources, there is much effort to explore better alternative cell sources. Desirable characteristics for such sources include accessibility, availability, and chondrogenic capacity. Consequently, stem cells such as adult mesenchymal stem cells (MSCs) have emerged as promising cell sources for articular cartilage tissue engineering. Chondrogenic potentials of MSCs from different tissues have also been investigated and compared. Specifically, MSCs from bone marrow are the most popular considering they are easily harvested (via the iliac crest) and have good chondrogenic potential. Many in vitro and in vivo studies have revealed promising results of marrowderived MSCs combined with various biomaterials or growth factors for repairing cartilage defects $[164,166]$. Recently, Johnson et al. describe the discovery and characterization of kartogenin, a small molecule that induced stem cells to take on the characteristics of chondrocytes and improves joint function and promotes the regeneration of cartilage in vivo in two rodent models of chronic and acute joint [166].

Mechanical stresses are an important factor of chondrocyte function as they stimulate them to increase the synthesis of ECM components. In cartilage culturing processes the main types of mechanical forces currently being investigated are hydrostatic pressure, direct compression, shear environments $[167,168]$.

Finally, to better recapitulate the ECM environment for cartilage tissue engineering, researchers have to introduce several biological signals, including chondroitin sulfate (CS), hyaluronic acid (HA), and collagen type I and II, into tissue-engineered scaffolds to encourage tissue specificity [169]. CS, hyaluronic acid, and collagen type II have been shown to promote or enhance chondrogenesis of mesenchymal stem cells (MSCs) in hydrogel-based culture systems. In addition to the physical cues of native matrix, cells are exposed to an array of biological cues throughout the ECM that direct cellular behavior. 
Cells are constantly interacting with the surrounding ECM, which gives rise to a dynamic transfer of information between the extracellular and intracellular space. In addition, biological trials in vitro be made taking into account the cell density for each zone [169].

Tissue engineering should be the best way to achieve successful cartilage regeneration by combining novel biologically inspired scaffolds approaches, nanotechnology, cell sources such as stem cells, chondrogenic factors, and physical stimuli [165].

\section{Author details}

Zaira Y. García-Carvajal ${ }^{1}$, David Garciadiego-Cázares ${ }^{1}$, Carmen Parra-Cid ${ }^{1}$, Rocío Aguilar-Gaytán ${ }^{1}$, Cristina Velasquillo ${ }^{3}$, Clemente Ibarra ${ }^{1,2}$ and Javier S. Castro Carmona ${ }^{4}$

1 Tissue Engineering, Cell Therapy and Regenerative Medicine Unit. Instituto Nacional de Rehabilitación, Secretaria de Salud. Mexico city, Mexico

2 Orthopaedic Surgery and Arthroscopy Servicie, Instituto Nacional de Rehabilitación, Secretaria de Salud. Mexico city, Mexico

3 Biotechnology Laboratory. Centro Nacional de Investigación y Atención al Quemado. Instituto Nacional de Rehabilitación, Secretaria de Salud. Mexico city, Mexico

4 Instituto de Ingenieria y Tecnologia. Universidad Autónoma de Ciudad Juárez, Juarez City, Chihuahua, Mexico

\section{References}

[1] Buckwalter, J.A., J.A. Martin, and T.D. Brown, Perspectives on chondrocyte mechanobiology and osteoarthritis. Biorheology 2004; 41(3-4):593-6.

[2] Benedek, T.G., A history of the understanding of cartilage. Osteoarthritis Cartilage 2006; 14(3) 203-9.

[3] Hunziker, E.B., T.M. Quinn, and H.J. Hauselmann, Quantitative structural organization of normal adult human articular cartilage. Osteoarthritis Cartilage, 2002; 10(7): 564-72, 2002.

[4] Goldring, M.B., Update on the biology of the chondrocyte and new approaches to treating cartilage diseases. Best Pract Res Clin Rheumatol, 2006; 20(5):1003-25.

[5] Goldring, M.B. and S.R. Goldring, Osteoarthritis. J Cell Physiol, 213(3): p. 626-34, 2007. 
[6] Saxne, T., et al., Inflammation is a feature of the disease process in early knee joint osteoarthritis. Rheumatology (Oxford), 2003; 42(7): 903-4.

[7] Sridhar, M.S., et al., Obesity and symptomatic osteoarthritis of the knee. J Bone Joint Surg Br, 94(4): p. 433-40, 2012.

[8] Issa, R.I. and T.M. Griffin. Pathobiology of obesity and osteoarthritis: integrating biomechanics and inflammation. Pathobiol Aging Age Relat Dis. 2012; 9 (2):17470.

[9] Ewers, B.J., et al., The extent of matrix damage and chondrocyte death in mechanically traumatized articular cartilage explants depend on rate of loading. J Orthop Res, 2001;19(5): 779-84.

[10] Tetsworth, K. and D. Paley, Malalignment and degenerative arthropathy. Orthop Clin North Am, 1994; 25(3): 367-77.

[11] Cerejo, R., et al., The influence of alignment on risk of knee osteoarthritis progression according to baseline stage of disease. Arthritis Rheum, 2002; 46(10):2632-6

[12] Tanamas, S., et al., Does knee malalignment increase the risk of development and progression of knee osteoarthritis? A systematic review. Arthritis Rheum, 2009; 61(4): 459-67.

[13] Fukuda, Y., et al., Impact load transmission of the knee joint-influence of leg alignment and the role of meniscus and articular cartilage. Clin Biomech (Bristol, Avon), 2000; 15(7):516-21.

[14] Lanzer, W.L. and G. Komenda, Changes in articular cartilage after meniscectomy. Clin Orthop Relat Res, 1990;252: 41-8.

[15] Musahl, V., et al., The effect of medial versus lateral meniscectomy on the stability of the anterior cruciate ligament-deficient knee. Am J Sports Med, 2010;38(8):1591-7.

[16] Berthiaume, M.J., et al., Meniscal tear and extrusion are strongly associated with progression of symptomatic knee osteoarthritis as assessed by quantitative magnetic resonance imaging. Ann Rheum Dis, 2005; 64(4): 556-63.

[17] Buckwalter, J.A., Articular cartilage injuries. Clin Orthop Relat Res, 2002; 402:21-37.

[18] Heir, S., et al., Focal cartilage defects in the knee impairs quality of life as much as severe osteoarthritis: a comparison of knee injury and osteoarthritis outcome score in 4 patient categories scheduled for knee surgery. Am J Sports Med, 2010; 38(2): 231-7.

[19] Lohmander, L.S., et al., The long-term consequence of anterior cruciate ligament and meniscus injuries: osteoarthritis. Am J Sports Med, 2007; 35(10):1756-69.

[20] Versier, G. and F. Dubrana, Treatment of knee cartilage defect in 2010. Orthop Traumatol Surg Res, 2011; 97(8 Suppl): S140-53.

[21] Eyre, D., Collagen of articular cartilage. Arthritis Res, 2002. 4(1): 30-5. 
[22] Hyc, A., et al., The morphology and selected biological properties of articular cartilage. Ortop Traumatol Rehabil, 2001; 3(2): 151-62.

[23] Poole, A.R., et al., Composition and structure of articular cartilage: a template for tissue repair. Clin Orthop Relat Res, 2001; 391 Suppl: S26-33.

[24] Korhonen, R.K., et al., Importance of collagen orientation and depth-dependent fixed charge densities of cartilage on mechanical behavior of chondrocytes. J Biomech Eng, 2008; 130(2): 021003.

[25] Huber, M., S. Trattnig, and F. Lintner, Anatomy, biochemistry, and physiology of articular cartilage. Invest Radiol, 2000; 35(10): 573-80.

[26] Schrobback, K., et al., Effects of oxygen on zonal marker expression in human articular chondrocytes. Tissue Eng Part A, 2012; 18(9-10): 920-33.

[27] Mobasheri, A., et al., Hypoxia inducible factor-1 and facilitative glucose transporters GLUT1 and GLUT3: putative molecular components of the oxygen and glucose sensing apparatus in articular chondrocytes. Histol Histopathol, 2005; 20(4):1327-38.

[28] Martel-Pelletier, J., et al., Cartilage in normal and osteoarthritis conditions. Best Pract Res Clin Rheumatol, 2008; 22(2): 351-84.

[29] Heijink, A., et al., Biomechanical considerations in the pathogenesis of osteoarthritis of the knee. Knee Surg Sports Traumatol Arthrosc, 2012; 20(3): 423-35.

[30] Silver, F.H., G. Bradica, and A. Tria, Relationship among biomechanical, biochemical, and cellular changes associated with osteoarthritis. Crit Rev Biomed Eng, 2001; 29(4): 373-91.

[31] Guilak, F., et al., The pericellular matrix as a transducer of biomechanical and biochemical signals in articular cartilage. Ann N Y Acad Sci, 2006;1068:498-512.

[32] Guilak, F., et al., The deformation behavior and mechanical properties of chondrocytes in articular cartilage. Osteoarthritis Cartilage, 1999; 7(1): 59-70.

[33] Eyre, D.R., M.A. Weis, and J.J. Wu, Articular cartilage collagen: an irreplaceable framework? Eur Cell Mater, 2006; 12: 57-63.

[34] Heinegard, D., Proteoglycans and more--from molecules to biology. Int J Exp Pathol, 2009; 90(6): 575-86.

[35] Gentili, C. and R. Cancedda, Cartilage and bone extracellular matrix. Curr Pharm Des, 2009; 15(12): 1334-48.

[36] Kim, S.H., J. Turnbull, and S. Guimond, Extracellular matrix and cell signalling: the dynamic cooperation of integrin, proteoglycan and growth factor receptor. J Endocrinol, 2011; 209(2):139-51.

[37] Shakibaei, M., C. Csaki, and A. Mobasheri, Diverse roles of integrin receptors in articular cartilage. Adv Anat Embryol Cell Biol, 2008; 197:1-60. 
[38] Vonwil, D., et al., An RGD-restricted substrate interface is sufficient for the adhesion, growth and cartilage forming capacity of human chondrocytes. Eur Cell Mater, 2010; 20: 316-28.

[39] Redini, F., Structure and regulation of articular cartilage proteoglycan expression. Pathol Biol, 2001; 49(4): 364-75.

[40] Bertrand, J., et al., Molecular mechanisms of cartilage remodelling in osteoarthritis. Int J Biochem Cell Biol, 2010; 42(10):1594-601.

[41] Struglics, A., et al., Human osteoarthritis synovial fluid and joint cartilage contain both aggrecanase- and matrix metalloproteinase-generated aggrecan fragments. Osteoarthritis Cartilage, 2006; 14(2): 101-13.

[42] Olsen, B. R. Morphogenesis: collagen it takes and bone it makes. Curr Biol 1996; 6, 645-647.

[43] Kannu, P., Bateman, J. F., Belluoccio, D., Fosang, A. J. \& Savarirayan, R. Employing molecular genetics of chondrodysplasias to inform the study of osteoarthritis. Arthritis Rheum 2009; 60, 325-334.

[44] Barsh, G. S. \& Byers, P. H. Reduced secretion of structurally abnormal type I procollagen in a form of osteogenesis imperfecta. PNAS USA 1981; 78, 5142-5146.

[45] Chan, D. \& Jacenko, O. Phenotypic and biochemical consequences of collagen X mutations in mice and humans. Matrix Biol 1998; 17, 169-184.

[46] Chen, F. H., Thomas, A. O., Hecht, J. T., Goldring, M. B. \& Lawler, J. Cartilage oligomeric matrix protein/thrombospondin 5 supports chondrocyte attachment through interaction with integrins. J Biol Chem 2005; 280, 32655-32661.

[47] Storm, E. E. et al. Limb alterations in brachypodism mice due to mutations in a new member of the TGF beta-superfamily. Nature 1994; 368, 639-643.

[48] Gualeni, B. et al. Defective proteoglycan sulfation of the growth plate zones causes reduced chondrocyte proliferation via an altered Indian hedgehog signalling. Matrix Biol 2020; 29, 453-460.

[49] Hargus, G. et al. Loss of Sox9 function results in defective chondrocyte differentiation of mouse embryonic stem cells in vitro. Int J Dev Biol 2008; 52, 323-332.

[50] Zhao, Q., Eberspaecher, H., Lefebvre, V. \& de Crombrugghe, B. Parallel expression of Sox9 and Col2a1 in cells undergoing chondrogenesis. Dev Dyn 1997; 209, 377-386.

[51] Lefebvre, V. \& Smits, P. Transcriptional control of chondrocyte fate and differentiation. Birth Defect Res C 2005; 75, 200-212.

[52] Vu, T. H. \& Werb, Z. Matrix metalloproteinases: effectors of development and normal physiology. Genes Dev 2000; 14, 2123-2133. 
[53] Chuang, C. Y. et al. The cartilage matrix molecule components produced by human foetal cartilage rudiment cells within scaffolds and the role of exogenous growth factors. Biomaterials 2012; 33, 4078-4088.

[54] Hynes, R. O. The extracellular matrix: not just pretty fibrils. Science 2009; 326, 12161219.

[55] Hirsch, M. S., Lunsford, L. E., Trinkaus-Randall, V. \& Svoboda, K. K. Chondrocyte survival and differentiation in situ are integrin mediated. Dev Dyn 1997; 210, 249 263.

[56] Shakibaei, M. \& Merker, H. J. Beta1-integrins in the cartilage matrix. Cell Tissue Res $1999 ; 296,565-573$.

[57] Bonnet, C. S. \& Walsh, D. A. Osteoarthritis, angiogenesis and inflammation. Rheumatology 20005; 44, 7-16.

[58] Jubeck, B., Muth, E., Gohr, C. M. \& Rosenthal, A. K. Type II collagen levels correlate with mineralization by articular cartilage vesicles. Arthritis Rheum 2009; 60, 27412746 .

[59] Little, C. B. et al. Matrix metalloproteinase 13-deficient mice are resistant to osteoarthritic cartilage erosion but not chondrocyte hypertrophy or osteophyte development. Arthritis Rheum 2009; 60, 3723-3733.

[60] Majumdar, M. K. et al. Double-knockout of ADAMTS-4 and ADAMTS-5 in mice results in physiologically normal animals and prevents the progression of osteoarthritis. Arthritis Rheum 2007; 56, 3670-3674.

[61] $\mathrm{Xu}$, L. et al. Increased expression of the collagen receptor discoidin domain receptor 2 in articular cartilage as a key event in the pathogenesis of osteoarthritis. Arthritis Rheum 2007; 56, 2663-2673.

[62] van der Kraan, P. M., Blaney Davidson, E. N., Blom, A. \& van den Berg, W. B. TGFbeta signaling in chondrocyte terminal differentiation and osteoarthritis: modulation and integration of signaling pathways through receptor-Smads. Osteoarthritis and Cartilage 2009; 17, 1539-1545.

[63] Yang, X. et al. TGF-\{beta\}/Smad3 signals repress chondrocyte hypertrophic differentiation and are required for maintaining articular cartilage. J Cell Biol 2001; 153, 35.

[64] Diarra, D. et al. Dickkopf-1 is a master regulator of joint remodeling. Nat Med 2007; 13, 156-163.

[65] Luyten, F. P., Tylzanowski, P. \& Lories, R. J. Wnt signaling and osteoarthritis. Bone 2009; 44, 522-527.

[66] Mateescu, R. G., Todhunter, R. J., Lust, G. \& Burton-Wurster, N. Increased MIG-6 mRNA transcripts in osteoarthritic cartilage. Biochem Biophys Res Commun 2005; 332, 482-486. 
[67] McGlashan, S. R., Haycraft, C. J., Jensen, C. G., Yoder, B. K. \& Poole, C. A. Articular cartilage and growth plate defects are associated with chondrocyte cytoskeletal abnormalities in Tg737orpk mice lacking the primary cilia protein polaris. Matrix Biol 2007; 26, 234-246.

[68] Poole, A. R. et al. Type II collagen degradation and its regulation in articular cartilage in osteoarthritis. Ann Rheum Dis 2002; 61 Suppl 2, ii78-81.

[69] Ionescu, A. M. et al. PTHrP modulates chondrocyte differentiation through AP-1 and CREB signaling. J Biol Chem 2001; 276, 11639-11647.

[70] Ohbayashi, N. et al. FGF18 is required for normal cell proliferation and differentiation during osteogenesis and chondrogenesis. Genes Dev 2002; 16, 870-879.

[71] Lanske, B. et al. PTH/PTHrP receptor in early development and Indian hedgehogregulated bone growth. Science 1996; 273, 663-666.

[72] Jay, G. D., Torres, J. R., Warman, M. L., Laderer, M. C. \& Breuer, K. S. The role of lubricin in the mechanical behavior of synovial fluid. PNAS USA 2007; 104, 61946199.

[73] Dowthwaite, G. P., Edwards, J. C. \& Pitsillides, A. A. An essential role for the interaction between hyaluronan and hyaluronan binding proteins during joint development. J Histochem Cytochem 1998; 46, 641-651.

[74] Koyama, E. et al. Synovial joint formation during mouse limb skeletogenesis: roles of Indian hedgehog signaling. Ann N Y Acad Sci 2007; 1116, 100-112.

[75] Archer, C. W., Dowthwaite, G. P. \& Francis-West, P. H. Development of synovial joints. Birth Defect Res C 2003; 69, 144-155.

[76] Hartmann, C. \& Tabin, C. J. Wnt-14 plays a pivotal role in inducing synovial joint formation in the developing appendicular skeleton. Cell 2001; 104, 341-351.

[77] Brunet, L. J., McMahon, J. A., McMahon, A. P. \& Harland, R. M. Noggin, cartilage morphogenesis, and joint formation in the mammalian skeleton. Science 1998; 280, 1455-1457.

[78] Garciadiego-Cázares, D., Rosales, C., Katoh, M. \& Chimal-Monroy, J. Coordination of chondrocyte differentiation and joint formation by alpha5beta1 integrin in the developing appendicular skeleton. Development 2004; 131, 4735-4742.

[79] Jones, D. C. et al. Uncoupling of growth plate maturation and bone formation in mice lacking both Schnurri-2 and Schnurri-3. PNAS USA 2010; 107, 8254-8258.

[80] Wu, Q., Zhang, Y. \& Chen, Q. Indian hedgehog is an essential component of mechanotransduction complex to stimulate chondrocyte proliferation. J Biol Chem 2001; 276, 35290-35296. 
[81] Kamekura, S. et al. Contribution of runt-related transcription factor 2 to the pathogenesis of osteoarthritis in mice after induction of knee joint instability. Arthritis Rheum 2006; 54, 2462-2470.

[82] Ornitz, D. M. \& Marie, P. J. FGF signaling pathways in endochondral and intramembranous bone development and human genetic disease. Genes Dev 2002; 16, 14461465.

[83] Legeai-Mallet, L., Benoist-Lasselin, C., Delezoide, A. L., Munnich, A. \& Bonaventure, J. Fibroblast growth factor receptor 3 mutations promote apoptosis but do not alter chondrocyte proliferation in thanatophoric dysplasia. J Biol Chem 1998; 273, 1300713014.

[84] Francis-West, P. H., Parish, J., Lee, K. \& Archer, C. W. BMP/GDF-signalling interactions during synovial joint development. Cell Tissue Res 1999; 296, 111-119.

[85] Francis-West, P. H. et al. Mechanisms of GDF-5 action during skeletal development. Development 1999; 126, 1305-1315.

[86] Reddi, A. H. Cartilage morphogenetic proteins: role in joint development, homoeostasis, and regeneration. Ann Rheum Dis 2003; 62 Suppl 2, ii73-8.

[87] Dell'Accio, F. et al. Activation of WNT and BMP signaling in adult human articular cartilage following mechanical injury. Arthritis Res Ther 2006; 8, R139.

[88] Dowthwaite, G. P. et al. The surface of articular cartilage contains a progenitor cell population. J Cell Sci 2004; 117, 889-897.

[89] Buckwalter J. A and Mankin H. J. “Articular cartilage: tissuedesign and chondrocytematrix interactions," Instructional course lectures, 1998 vol. 47, pp. 477-486.

[90] Hunziker EB. Articular cartilage repair: basic science and clinical progress. A review of the current status and prospects. Osteoarthritis Cartilage. 2002 Jun; 10(6):432-63.

[91] Noyes FR, Bassett RW, Grood ES, Butler DL. Arthroscopy in acute traumatic hemarthrosis of the knee. Incidence of anterior cruciate tears and other injuries. J Bone Joint Surg Am. 1980 Jul;62 (5):687-95, 757.

[92] Hjelle K, Solheim E, Strand T, Muri R, Brittberg M. Articular cartilage defects in 1,000 kneearthroscopies. Arthroscopy, 2002 18:730-734.

[93] Curl WW, Krome J, Gordon ES, Rushing J, Smith BP, Poehling GG.Cartilage injuries: a review of 31,516 knee arthroscopies. Arthroscopy, 1997 13:456-460.

[94] Pridie K. A method of resurfacing osteoarthritis knee joints. J bone joint surg. br. 1959 41:618-619.

[95] Steadman JR, Rodkey WG, Briggs KK, Rodrigo JJ. The microfracture technician the management of complete cartilage defects in the knee joint. Orthopedic. 1999 28:26-32. 
[96] Magnuson PB. The classic: Joint debridement: surgical treatment of degenerative arthritis. Clin Orthop Relat Res. 1974 Jun; (101):4-12.

[97] Pridie K. A method of resurfacing osteoarthritis knee joints. J bone joint surg. br. 1959 41:618-619.

[98] Trattnig S, Pinker K, Krestan C, Plank C, Millington S, Marlovits S. Matrix-based autologous chondrocyte implantation for cartilage repair with HyalograftC: two-year follow-up by magnetic resonance imaging. Eur J Radiol. 2006 Jan;57(1):9-15.

[99] Knutsen G, Drogset JO, Engebretsen L, Grøntvedt T, Isaksen V, Ludvigsen TC, Roberts S, Solheim E, Strand T, Johansen O. A. Randomized trial comparing autologous chondrocyte implantation with microfracture. Findings at five years. J Bone Joint Surg Am 2007 Oct; 89(10):2105-12.

[100] Lassandro F, Romano S, Ragozzino A, Rossi G, Valente T, Ferrara I, Romano L, Grassi R. Role of helical CT in diagnosis of gallstone ileus and related conditions. AJR Am J Roentgenol. 2005 Nov. 185 (5):1159-65,

[101] Knutsen G, Engebretsen L, Ludvigsen TC, Drogset JO, Grøntvedt T, Solheim E, Strand T, Roberts S, Isaksen V, Johansen O. 2004. Autologous chondrocyte implantation compared with microfracture in the knee. A randomized trial. J Bone Joint Surg Am. 2004 Mar; 86-A(3):455-64.

[102] Henderson I, Lavigne P, Valenzuela H, Oakes B. Autologous chondrocyte implantation: superior biologic properties of hyaline cartilage repairs. Clin Orthop Relat Res. 2007 Feb; 455:253-61, 2007.

[103] Hallal PC, Wells JC, Bertoldi AD, Gazalle FK, Silva MC, Domingues MR, Carret ML, Araújo CL, Gigante DP. A shift in the epidemiology of low body mass index in Brazilian adults. Eur J Clin Nutr. 2005 Sep; 59 (9):1002-6.

[104] Knutsen G, Drogset JO, Engebretsen L, Grøntvedt T, Isaksen V, Ludvigsen TC, Roberts S, Solheim E, Strand T, Johansen O. A. Randomized trial comparing autologous chondrocyte implantation with microfracture. Findings at five years. J Bone Joint Surg Am. 2007 Oct; 89 (10):2105-12.

[105] Leumann A, Wiewiorski M, Egelhof T, Rasch H, Magerkurth O, Candrian C, Schaefer DJ, Martin I, Jakob M, Valderrabano V. Radiographic evaluation of frontal talar edge configuration for osteochondral plug transplantation. Clin Anat. 2009 Mar; 22(2):261-6.

[106] Reguzzoni M, Manelli A, Ronga M, Raspanti M, Grassi FA. Histology and ultrastructure of a tissue-engineered collagen meniscus before and after implantation. J Biomed Mater Res B Appl. Biomater. 2005 Aug ;74 (2):808-16.

[107] Hangody L, Kish G, Kárpáti Z, Szerb I, Udvarhelyi I. Arthroscopic autogenousosteochondralmosaicplasty for the treatment of femoral condylar articular defects. A preliminary report. Knee Surg Sports Traumatol Arthrosc. 1997;5 (4):262-7. 
[108] Coen G, Moscaritolo E, Catalano C, Lavini R, Nofroni I, Ronga G, Sardella D, Zaccaria $A$, Cianci $R$. Atherosclerotic renal artery stenosis: one year outcome of total and separate kidney function following stenting. BMC Nephrol. 2004 Oct 15;5:15.

[109] Richardson JB, Caterson B, Evans EH, Ashton BA, Roberts S. 1999. Repair of human articular cartilage after implantation of autologous chondrocytes. J Bone Joint Surg Br. 1999 Nov;81(6):1064-8.

[110] Brittberg M, Lindahl A, Nilsson A, Ohlsson C, Isaksson O, Peterson L. Treatment of deep cartilage defects in the knee with autologous chondrocyte transplantation. $\mathrm{N}$ Engl J Med. 1994 Oct 6; 331(14):889-95.

[111] Franceschi F, Longo UG, Ruzzini L, Marinozzi A, Maffulli N, Denaro V. Simultaneous arthroscopic implantation of autologous chondrocytes and high tibial osteotomy for tibialchondral defects in the varus knee. Knee. 2008 Aug;15 (4):309-13.

[112] Bahuaud J, Maitrot RC, Bouvet R, Kerdiles N, Tovagliaro F, Synave J, Buisson P, Thierry JF, Versier A, Romanet JP, Chauvin F, Gillet JP, Allizard JP, de Belenet H. Implantation of autologous chondrocytes for cartilagenous lesions in young patients. A study of 24 cases. Chirurgie. 1998 Dec;123 (6):568-71.

[113] Bartlett W, Skinner JA, Gooding CR, Carrington RW, Flanagan AM, Briggs TW, Bentley G. Autologous chondrocyte implantation versus matrix-induced autologous chondrocyte implantation for osteochondral defects of the knee: a prospective, randomised study. J Bone Joint Surg Br. 2005 May;87 (5):640-5.

[114] Barlic A, Drobnic M, Malicev E, Kregar-Velikonja N. Quantitative analysis of gene expression in human articular chondrocytes assigned for autologous implantation. J Orthop Res. 2008 Jun;26(6):847-53.

[115] Masri M, Lombardero G, Velasquillo C, Martínez V, Neri R, Villegas H, Ibarra C. Matrix-encapsulation cell-seeding technique to prevent cell detachment during arthroscopic implantation of matrix-induced autologous chondrocytes. Arthroscopy. 2007Aug; 23(8):877-83.

[116] Chaipinyo K, Oakes BW, Van Damme MP. The use of debrided human articular cartilage for autologous chondrocyte implantation: maintenance of chondrocyte differentiation andproliferation in type I collagen gels. J Orthop Res. 2004 22:446-455.

[117] Grande DA, Halberstadt C, Naughton G, Schwartz R, Manji R. Evaluation of matrix scaffolds for tissue engineering of articular cartilage grafts. J Biomed Mater Res. 1997 34:211-220.

[118] Chen WY, Abatangelo G. Functions of hyaluronan in wound repair. Wound Repair Regen. 19997:79-89.

[119] Marcacci M, Berruto M, Brocchetta D, Delcogliano A, Ghinelli D, Gobbi A, Kon E, Pederzini L, Rosa D, Sacchetti GL, Stefani G, Zanasi S. Articular cartilage engineering with Hyalograft C: 3-year clinical results. Clin Orthop Relat Res.2005 435:96-105. 
[120] Aigner J, Tegeler J, Hutzler P, Campoccia D, Pavesio A, Hammer C, Kastenbauer E, Naumann A. Cartilage tissue engineering with novel nonwoven structured biomaterial based on hyaluronic acid benzyl ester. J Biomed Mater Res. 1998 42:172-181.

[121] Brun P, Abatangelo G, Radice M, Zacchi V, Guidolin D, Daga Gordini D, Cortivo R. Chondrocyte aggregation and reorganization into three-dimensional scaffolds. J Biomed Mater Res. 1999 46:337-346.

[122] Grigolo B, Lisignoli G, Piacentini A, FioriniM, Gobbi P,Mazzotti G, Duca M, Pavesio A, Facchini A. Evidence for redifferentiation of human chondrocytes grown on a hyaluronan-based biomaterial (HYAff 11): molecular, immunohistochemical and ultrastructural analysis. Biomaterials. 2002 23:1187-1195.

[123] Kirilak Y, Pavlos NJ, Willers CR, Han R, Feng H, Xu J, Asokananthan N, Stewart GA, Henry P, Wood D, Zheng MH. Fibrin sealant promotes migration and proliferation of human articular chondrocytes: possible involvement of thrombin and protease-activated receptors. Int J Mol Med. 2006 17:551-558.

[124] Van Susante JL, Buma P, Schuman L, Homminga GN, van den Berg WB, Veth RP. Resurfacing potential of heterologous chondrocytes suspended in fibrin glue in large full-thickness defects of femoral articular cartilage: an experimental study in the goat. Biomaterials. 1999 20:1167-1175.

[125] Kawabe N, Yoshinao M. The repair of full-thickness articular cartilage defects. Immune responses to reparative tissue formed by llogeneic growth plate chondrocyte implants. Clin Orthop Relat Res. 1991 268:279-293.

[126] Cherubino P, Grassi FA, Bulgheroni P, Ronga M. Autologous chondrocyte implantation using a bilayer collagen membrane: a preliminary report. J Orthop. Surg. 2003 11:10-15.

[127] Pavesio A, Abatangelo G, Borrione A, Brocchetta D, Hollander AP, Kon E, Torasso F, Zanasi S, Marcacci M. Hyaluronan- based scaffolds (Hyalograft C) in the treatment of knee cartilage defects: preliminary clinical findings. Novartis Found Symp. 2003 249:203-217.

[128] Visna P, Pasa L, Cizma'r I, Hart R, Hoch J. Treatment of deep cartilage defects of the knee using autologous chondrograft transplantation and by abrasive techniques-a randomized controlled study. Acta Chir Belg. 2004 104:709-714.

[129] Gikas PD, Bayliss L, Bentley G, Briggs TW. An overview of autologous chondrocyte implantation .J Bone Joint Surg. Br. 2009 Aug; 91(8):997-1006.

[130] Manfredini M, Zerbinati F, Gildone A, Faccini R. Autologous chondrocyte implantation: a comparison between an open periosteal-covered and an arthroscopic matrixguided technique. Acta Orthop. Belg. 2007 73:207-218. 
[131] Behrens P, Bitter T, Kurz B, Russlies M. Matrix-associated autologous chondrocyte transplantation/implantation (MACT/MACI)-5-year follow-up. Knee. 2006 13:194202.

[132] Bartlett W, Gooding CR, Carrington RW, Skinner JA, Briggs TW, Bentley G. Autologous chondrocyte implantation at the knee using a bilayer collagen membrane with bone graft. A preliminary report. J Bone Joint Surg. Br. 2005 Mar; 87(3):330-2.

[133] Schneider U, Rackwitz L, Andereya S, Siebenlist S, Fensky F, Reichert J, Löer I, Barthel T, Rudert M, Nöth U. A prospective multicenter study on the outcome of type I collagen hydrogel-based autologous chondrocyte implantation (CaReS) for the repair of articular cartilage defects in the knee. Am J Sports Med. 2011 Dec; 39 (12):2558-65.

[134] Rackwitz L, Schneider U, Andereya S, Siebenlist S, Reichert JC, Fensky F, Arnhold J, Löer I, Grossstück R, Zinser W, Barthel T, Rudert M, Nth U. Reconstruction of osteochondral defects with a collagen I hydrogel. Results of a prospective multicenter study. Orthopade. 2012 Apr; 41(4):268-79.

[135] Della Villa S, Kon E, Filardo G, Ricci M, Vincentelli F, Delcogliano M, Marcacci M. Does intensive rehabilitation permit early return to sport without compromising the clinical outcome after arthroscopic autologous chondrocyte implantation in highly competitive athletes? Am J Sports Med. 2010 Jan; 38(1):68-77.

[136] Grigolo B, Lisignoli G, Piacentini A, FioriniM, Gobbi P,Mazzotti G, Duca M, Pavesio A, Facchini A. Evidence for redifferentiation of human chondrocytes grown on a hyaluronan-based biomaterial (HYAff 11): molecular, immunohistochemical and ultrastructural analysis. Biomaterials. 2002 23:1187-1195.

[137] Solchaga LA, Dennis JE, Goldberg VM, Caplan .I. Hyaluronic acid-based polymers as cell carriers for tissue engineered repair of bone and cartilage.J Orthop. Res. 1999 Mar; 17(2):205-13.

[138] Selmi TA, Verdonk P, Chambat P, Dubrana F, Potel JF, Barnouin L, Neyret P. Autologous chondrocyte implantation in a novel alginate-agarose hydrogel: outcome at two years. J Bone Joint Surg. Br. 2008 90:597-604.

[139] Kyoung-Hwan Choi, Byung Hyune Choi, So Ra Park, Byoung Ju Kim, Byoung-Hyun Min. The chondrogenic differentiation of mesenchymal stem cells on an extracellular matrix scaffold derived from porcine chondrocytes. Biomaterials 2010; 31: 5355-5365.

[140] Nicodemus GD, Bryant SJ. Cell Encapsulation in Biodegradable Hydrogels for Tissue Engineering Applications. Tissue Eng Part B Rev. 2008;14 (2): 149-65.

[141] Ge Z, Li C, Heng BC, Cao G, Yang Z. Functional biomaterials for cartilage regeneration. J Biomed Mater Res A. 2012; 100 (9):2526-36.

[142] Coates Emily E, Fisher John P. Robert L. In Burdick, Jason A.; Mauck, editors. Biomaterials for Tissue Engineering Applications: A Review of the Past and Future Trends- 
Cartilage Engineering: Current Status and Future Trends, Springer;2011; 279-306. http://rd.springer.com/book/10.1007/978-3-7091-0385-2/page/1

[143] Chung-Hwan B, Ye-Jeung K. Characteristics of Tissue-Engineered Cartilage on Macroporous Biodegradable PLGA Scaffold. Laryngoscope. 2006 116: 1829-1834.

[144] [2]Diaz-Romero J, Gaillard JP, Grogan SP, Nesic D, Trub T, Mainil-Varlet P. Immunophenotypic analysis of human articular chondrocytes: Changes in surface markers associated with cell expansion in monolayer culture. J Cell Physiol. 2005 202:731-742.

[145] Hiroyuki Miyajima et al. Hydrogel-based biomimetic enviroment for in vitro modulation of branching morphogenesis. Biomaterials. 2011 32: 6754-6763.

[146] Sun-Young C, Cross D, and Wang C. Facile Synthesis and Characterization of Disulfide-Cross-Linked Hyaluronic Acid Hydrogels for Protein Delivery and Cell Encapsulation. Biomacromolecules. 2011 12: 1126-1136.

[147] Leda Clouda, et al. Thermoresponsive, in situ cross-linkable hydrogels based on Nisopropylacrylamide: Fabrication, characterization and mesenchymal stem cell encapsulation. Acta biomateriala. 2011 7: 1460-1467.

[148] Vinatier C, Guicheuxa J, Daculsi G, Layrolle P, and Weiss P. Cartilage and bone tissue engineering using Hydrogels. Bio-Medical Materials and Engineering. 200616.

[149] Nicola C. Hunt and Liam M. Grover. Cell encapsulation using biopolymer gels for regenerative Medicine. Biotechnol Lett. 2010 32:733-742.

[150] Peppas, N.A. Hydrogels in medicine and pharmacy. 1987 CRC Press, Boca Raton, FL.

[151] Sandra Cram, Hugh Brown, Geoff Spinks, Dominique Hourdet, Costantino Creton. Hydrophobically Modified Acrylamide Based Hydrogels Proc. of SPIE. 2005 5648:153-162.

[152] Kong HJ, Kim CJ, Huebsch N, Weitz D, and Mooney DJ. Noninvasive Probing of the Spatial Organization of Polymer Chains in Hydrogels Using Fluorescence Resonance Energy Transfer (FRET) J. AM. CHEM. SOC. 2007 129(15): 4518.

[153] Stammen JA, Williams S, Ku DN, Guldberg RE. Mechanical properties of a novel PVA hydrogel in shear and unconfined compression. Biomaterials. 2001 22:799-806.

[154] Zheng-Qiu G, Jiu-Mei X, Xiang-Hong Z. The development of artificial articular cartilage - PVA-hydrogel. Biomed Mater Engng. 1998 8:75-81.

[155] Kavanagh GM \& Ross-Murphy SB. Rheological characterisation of polymer gels. Progress in Polymer Science. 1998 23:533-562.

[156] Barrangou LM, Daubert CR, Foegeding EA. Textural properties of agarose gels. I. Rheological and fracture properties. Food Hydrocolloids. 2006 20:184-195.

[157] Peppas NA. Hydrogels. In: Ratner B. (ed.) Biomaterial Science. An introduction to materials in medicine. Elsevier Academic Press. San Diego, Cal. 2004 p.100-112. 
[158] Klein TJ, Malda J, Sah RL, Hutmacher DW. Tissue Engineering of Articular Cartilage with Biomimetic Zones. Tissue Eng Part B Rev. 2009; 15(2):143-57.

[159] Sharma B, Williams CG, Kim TK, Sun D, Malik A, Khan M, Leong K, Elisseeff JH. Designing zonal organization into tissue-engineered cartilage. Tissue Engineering 2007; 13(2): 405-414.

[160] Hwang NS, Varghese S, Lee HJ, Theprungsirikul P, Canver A, Sharma B, Elisseeff J. Response of zonal chondrocytes to extracellular matrix-hydrogels. FEBS Lett. 2007; 581(22):4172-4178.

[161] Melero-Martin, J.M, Al-Rubeai. In N. Ashammakhi, R. L. Reis, E. Chiellini editors. Topics in Tissue Engineering; In Vitro Expansion of Chondrocytes; 2007 (3). http:// www.oulu.fi/spareparts/ebook_topics_in_t_e_vol3/abstracts/al-rubeai_chapter_01.pdf

[162] Unterman SA, Gibson M, Lee JH, Crist J, Chansakul T, Yang EC, Elisseeff JH. Hyaluronic Acid-Binding Scaffold for Articular Cartilage Repair. Tissue Eng Part A. 2012; doi:10.1089/ten.tea.2011.0711

[163] Concaro S, Nicklasson E, Ellowsson L, Lindahl A, Brittberg M, Gatenholm P. Effect of cell seeding concentration on the quality of tissue engineered constructs loaded with adult human articular chondrocytes. J Tissue Eng Regen Med. 2008; 2(1):14-21.

[164] Chen FH, Rousche KT, Tuan RS. Technology Insight: adult stem cells in cartilage regeneration and tissue engineering. Nat Clin Pract Rheumatol. 2006; 2(7): 373-82.

[165] Zhang L, Hu J, Athanasiou KA. The Role of Tissue Engineering in Articular Cartilage Repair and Regeneration. Crit Rev Biomed Eng. 2009; 37(1-2): 1-57.

[166] Johnson K, Zhu S, Tremblay MS, Payette JN, Wang J, Bouchez LC, Meeusen S, Althage A, Cho CY, Wu X, Schultz PG. A stem cell-based approach to cartilage repair. Science. 2012; 336 (6082): 717-721.

[167] Chen T, Buckley M, Cohen I, Bonassar L, Awad HA. Insights into interstitial flow, shear stress, and mass transport effects on ECM heterogeneity in bioreactor-cultivated engineered cartilage hydrogels. Biomech Model Mechanobiol. 2012; 11(5):689-702.

[168] McMahon L.A, Barron, V., Prina-Mello, A. In P.J. Prendergast and P.E. McHugh editors. Topics in Bio-Mechanical Engineering - The state-of-the-art in cartilage bioreactors. Trinity Centre for Bioengineering \& the National Centre for Biomedical Engineering Science, 2004; 94-146. http://www.tcd.ie/bioengineering/documents/ ChapterIV.pdf

[169] Responte DJ, Natoli RM, Athanasiou KA. Identification of potential biophysical and molecular signalling mechanisms underlying hyaluronic acid enhancement of cartilage formation. Soc. Interface, 2012; doi:10.1098/rsif.2012.0399 
